\title{
Enhancement of reactive oxygen species formation in stable and unstable asthmatic patients
}

\author{
I. Vachier*, P. Chanez**, C. Le Doucen*, M. Damon*+, B. Descomps*, P. Godard**
}

Enhancement of reactive oxygen species formation in stable and unstable asthmatic patients. I. Vachier, P. Chanez, C. Le Doucen, M. Damon, B. Descomps, P. Godard. CERS Journals Ltd 1994.

ABSTRACT: There is increasing evidence to suggest that human blood polymorphonuclear neutrophils (PMNs) and monocytes play an important role in the inflammatory processes of asthma. In asthmatic patients, PMNs and monocytes were shown to be activated more than in healthy subjects.

We investigated the capacity of these two cell populations to generate reactive oxygen species (ROS) in stable and unstable asthmatic patients. The two populations of asthmatic patients were identified by asthma activity, as expressed by clinical events occurring within 2 weeks prior to the study. Oxygen species formation was analysed for isolated purified PMNs and monocytes (Mos) by chemiluminescence (CL) using lucigenin and luminol as luminescent probes. CL was determined on nonstimulated and on phorbol myristate acetate (PMA)-stimulated cells. The stimulatability coefficient (PMA-stimulated/nonstimulated cell ratio) of each cell population was then calculated.

Resting PMNs and Mos generated significantly greater amounts of ROS in stable asthmatic patients, and much more in unstable asthmatic patients, as compared to healthy subjects, both in lucigenin and luminol enhanced CL. Non $\mathrm{O}_{2} .^{-} \mathrm{ROS}$ production from PMA-stimulated PMNs and Mos was identical in unstable asthmatic patients and in healthy subjects, whereas a significant decrease was observed in stable asthmatic patients, as assessed by luminol enhanced CL. PMA-stimulated cells showed no difference in $\mathrm{O}_{2}^{-}$generation, as assessed by lucigenin enhanced $C L$. However, the stimulatability coefficient of all asthmatic patients was always significantly lower than that of healthy subjects.

These results suggest that there are differences in priming and stimulation of Ros production from PMNs and Mos between stable and unstable asthmatic patients. Release of oxygen species from these cells may be implicated in the pathophysiology of unstable asthma.

Eur Respir J., 1994, 7, 1585-1592.
*INSERM Unité 58, Montpellier, France. **Cliniques des Maladies Respiratoires and CJF-INSERM 9210, Hôpital Arnaud de Villeneuve, Montpellier, France.

Correspondence: I. Vachier

CJF INSERM 9210

Hôpital Arnaud de Villeneuve

34295 Montpellier Cedex 5

France

Keywords: Asthma activity monocytes

oxygen species

polymorphonuclear neutrophils

Received: December 221993

Accepted after revision June 231994

+This work is dedicated to Dr Marcelle Damon, deceased 1994.

This work was partly supported by a grant from the Comité Départemental de Lutte contre les Maladies Respiratoires, Mont-
Bronchial asthma can be considered as a combination of reversible airway obstruction, increased airway responsiveness and airway inflammation. Various cells which migrate from the bloodstream into the bronchial tree are known to be sources of local inflammation [1].

In a previous study, using chemiluminescence (CL) analysis, we showed that alveolar macrophages from asthmatic patients were activated [2]. As assessed by the release of reactive oxygen species (ROS), this activation was correlated with the severity of asthma defined by the Aas' clinical score [3], which takes into account asthmatic events during the last year. Similarly, blood monocytes (Mos), which are precursors of macrophages, were activated and released higher quantities of ROS in asthmatic patients [4]. Several investigators have also suggested that polymorphonuclear neutrophils (PMNs) from asthmatic patients generate more ROS than those of healthy subjects $[5,6]$. This activation is correlated with bronchial hyperreactivity [5]. We thus hypothesized that activation of blood PMNs and Mos could be correlated with the activity of asthma, that is instability or stability, which takes into account asthmatic events over a short period of time (10-15 days).

The final expression of asthma depends on different interactions between the inflammatory cells and on their activation state expressed by the release of numerous mediators. Among them, oxygen radicals and their metabolites, such as superoxide anion $\left(\mathrm{O}_{2}{ }^{-}\right)$, hydrogen peroxide $\left(\mathrm{H}_{2} \mathrm{O}_{2}\right)$ and hydroxyl radical $\left(\mathrm{OH}^{\circ}\right)$ are important agents causing lung tissue damage in inflammatory processes. These ROS are produced after activation of the nicotinamide adenine dinucleotide phosphate reduced form (NADPH) oxidase system, particularly in phagocytic cells, such as polymorphonuclear and mononuclear cells [7-9]. They can be analysed through their ability to generate luminescence, as amplified by specific probes and measured by a photon counter analyser [10]. 
The aim of this study was to investigate the capacity of blood leucocytes, PMNs, and Mos, from two different populations of asthmatic patients to generate ROS as compared to cells from healthy subjects. These two populations were classified according to activity of asthma, as described by TURNER WARWICK [11] and ourselves [12], rather than by severity as defined by the Aas' score. Phorbol myristate acetate (PMA) [13] was used for in vitro triggering of a protein kinase $\mathrm{C}$ activator which stimulates the NADPH oxidase system [14]. This unphysiological stimulus was used to obtained a maximal level of stimulation to make possible comparison between the three groups of subjects.

\section{Methods}

\section{Patients}

Nine healthy volunteers, aged 22-69 yrs (mean \pm SEM $43 \pm 4 \mathrm{yrs}$ ), and 14 patients with asthma, aged 19-66 yrs (44 \pm 4 yrs) were studied. Asthma was diagnosed according to the American Thoracic Society Statement [15]. All subjects were nonsmokers.

The severity of asthma was determined according to Aas' clinical score [3] used to grade chronic asthma from very mild forms (score $=1$ ) to incapaciting disease requiring permanent medication (score $=5$ ). The grading is based on clinical events which took place during the previous year and combines symptoms (number and duration of asthma episodes, total duration of symptoms, presence or absence of symptom-free intervals between attacks) and the requirement for medication. It does not take into account the pulmonary function of the patients. Activity of asthma (stability versus instability) was established by a questionnaire as described previously [12]. Briefly, the stability of asthma was defined as the absence of any clinical events or $\beta_{2}$-agonist inhalation during the last 2 weeks. The instability of asthma was defined by the presence of any of the following symptoms: cough, dyspnoea, wheezing, breathlessness, $\beta_{2}$-agonist consumption during the last two weeks. The time of the last asthma attack was defined by the last $\beta_{2}$-agonist inhalation,

Forced expiratory volume in one second $\left(\mathrm{FEV}_{1}\right)$ was measured just before venepuncture. Allergy was assessed by clinical history, the presence of at least three positive skin tests and high immunoglobulin $\mathrm{E}$ ( $\mathrm{IgE}$ ) levels in the blood. Disodium cromoglycate, nedocromil sodium and inhaled corticosteroids had to have been interrupted for at least 1 month. Stable asthmatic patient were without any treatment. Unstable patients were treated only with $\beta_{2}$-agonists. They did not use theophylline or oral corticosteroids. None of the healthy volunteers were using medication.

Since $\beta_{2}$-agonists can modify the state of blood cell activation in unstable asthmatic patients, three additional healthy subjects were enrolled in the study. A first venepuncture was performed at 8 a.m. The subjects then inhaled $\beta_{2}$-agonist (terbutaline sulphate $1 \mathrm{mg}$ ) and a second venepuncture was performed 30 min after inhalation

The study was performed after informed consent and fulfilled the criteria of the Ethics Committee of the University of Montpellier.

\section{Cell preparations}

Peripheral blood was recovered by venepuncture using heparin $\left(25 \mathrm{U} \cdot \mathrm{ml}^{-1}\right)$ as anticoagulent. Cells were isolated by centrifugation of blood samples over isotonic Percoll solutions (Kabi Phamacia, France) [16] with densities of $1.097(72 \%)$ and $1.086 \mathrm{~g} \cdot \mathrm{ml}^{-1}(63 \%)$. A $5 \mathrm{ml}$ volume of $63 \%$ Percoll solution was layered over $5 \mathrm{ml}$ of $72 \%$ solution in a $15 \mathrm{ml}$ conical tube. Whole blood $(5 \mathrm{ml})$ was layered over the Percoll gradient and then centrifuged at $400 \times \mathrm{g}$ for $20 \mathrm{~min}$ at room temperature, resulting in the formation of one band of mononuclear cells (MNs) and bands of PMNs above the $72 \%$ layer. The MN suspension and then the PMN suspension in Percoll were removed and washed once with an equal volume of saline solution. For both populations, contaminating erythrocytes were lysed by incubation for $10 \mathrm{~min}$ in a buffer solution of $130 \mathrm{mmol} \cdot l^{-1} \mathrm{NH}_{4} \mathrm{Cl}, 10$ $\mathrm{mmol} \cdot l^{-1}$ Tris, and $16 \mathrm{mmol} \cdot l^{-1} \mathrm{~K}_{2} \mathrm{CO}_{3}, \mathrm{pH} 7.4$, and recovered by centrifugation. Cells were then washed in saline solution and counted in the initial suspension.

Purity of PMNs (95\%) was evaluated by cytocentrifugation and May-Grünwald staining. They were then suspended in medium 199 (Gibco Chemical, Scotland) to obtain a concentration of $5 \times 10^{5} \mathrm{PMNs}$ for 800 $\mu \mathrm{l}$ of medium.

MNs were first counted using neutral red staining specific to Mos in proportion to neutral red MNs, 3:1. They $\left(10 \times 10^{6} \mathrm{Mo} \cdot \mathrm{ml}^{-1}\right)$ were then incubated in Petri dishes with $5 \mathrm{ml}$ RPMI 1640 medium (Gibco) and 20\% foetal calf serum (FCS) (Gibco) for $2 \mathrm{~h}$ at $37^{\circ} \mathrm{C}$ in a humid atmosphere of $95 \%$ air and $5 \% \mathrm{CO}_{2}$ to separate adherent Mos from suspended lymphocytes. At the end of this incubation, nonadherent cells were removed. Adherent Mos were recovered by gentle scraping with a rubber policeman into RPMI 1640 medium, and then characterized by May-Grünwald staining (purity 95\%). Both cell populations (PMNs and Mos) were resuspended in RPMI 1640 medium to obtain a concentration of $5 \times 10^{5}$ PMNs or Mos in $800 \mu$ l of medium.

Viability of the two cell populations was determined by the trypan blue exclusion test, and was always greater than $95 \%$.

\section{CL measurements}

Reactive oxygen species (ROS)-induced CL was measured using luminol [17, 18] and lucigenin [19, 20] as luminescent probes.

Luminol (Sigma, St Louis, MO, USA) was used to enhance the luminescence induced by the whole set of ROS. Luminol $(18 \mathrm{mg}$ ) was suspended in a $1 \%$ solution of bovine serum albumin (BSA) (Sigma) in $100 \mathrm{ml}$ phosphate-buffered saline (PBS) $(\mathrm{pH} \mathrm{7.4)}$ to obtain a 
stock solution of $10^{-3} \mathrm{~mol} \cdot l^{-1}$ luminol concentration. The final concentration was $10^{-4} \mathrm{~mol} \cdot l^{-1}$.

Lucigenin (Sigma) was used to enhance luminescence induced by superoxide anion $\left(\mathrm{O}_{2^{-}}{ }^{-}\right)$production. Lucigenin $(5 \mathrm{mg})$ was dissolved in $100 \mathrm{ml}$ medium 199 containing $476 \mathrm{mg}$ hydroxyethyl piperazine ethanesulphonic acid (HEPES) (Sigma) and $100 \mathrm{mg}$ gelatin with heating to obtain a stock solution of $10^{-4} \mathrm{~mol} \cdot l^{-1}$ lucigenin concentration. The final concentration was $10^{-5}$ mol $\cdot l^{-1}$.

PMA (Sigma) was dissolved as stock solution of 1 $\mathrm{mg} \cdot \mathrm{ml}^{-1}$ in dimethyl sulphoxide (DMSO) (Sigma) maintained at $-70^{\circ} \mathrm{C}$. Before use, the stock solution was diluted in saline solution to obtain a $10^{-7} \mathrm{~mol} \cdot l^{-1}$ final concentration in PMA.

CL was monitored in a model 1251 LKB Wallac luminometer (Wallac Co., Turku, Finland) connected to an Apple computer. All procedures were performed in the dark. Medium $(800 \mu \mathrm{l})$ containing $5 \times 10^{5}$ purified PMNs or Mos were placed in luminometer vials at $37^{\circ} \mathrm{C}$ with continuous stirring. Firstly, $100 \mu \mathrm{l}$ of luminescent probe was added and a basal value was determined, then $100 \mu \mathrm{l}$ PMA was added and measurements were taken every minute for 20 or $30 \mathrm{~min}$. Spontaneous formation of oxygen species (without PMA) was also analysed simultaneously. The kinetic study of nonstimulated or PMA-stimulated cell responses was performed in duplicate, and the results were analysed as CL peaks (maximal value obtained without any stimulation or after stimulation) for lucigenin and luminol, and expressed as $\mathrm{mV}$ per $5 \times 10^{5}$ cells.

\section{Study design and statistical analysis}

Samples were recovered at 8 a.m. and studied without delay. PMNs and Mos were isolated from the whole blood. The CL response was analysed on the two cell populations for each subject. The CL peak was defined as the maximum CL obtained after PMA-stimulation. All results were expressed as mean \pm SEM.

The significance levels between CL peaks in PMAstimulated and nonstimulated cells from stable and unstable asthmatic patients, and healthy subjects were determined by the nonparametric Mann-Whitney U-test. Differences between stable and unstable asthmatic patients were also analysed in the same way.

The ratio for the CL peak in PMA-stimulated cells/CL peak in nonstimulated cells was also given as a coefficient of cell stimulatability between the spontaneous stimulation of cells and the stimulation of these cells after PMA-stimulation.

\section{Results}

\section{Clinical story of subjects}

Both groups of patients were identified as described in table 1 , based on the activity of asthma (stable versus unstable). Seven patients were unstable asthmatic patients, and the last asthma attack was ranked at 12, 18 and $24 \mathrm{~h}$ before the analysis. Seven patients were stable asthmatic patients.

There were nine female and five male patients. Six patients presented positive skin tests for common aeroallergens. The Aas' score was 1 in four patients, 2 in four, 3 in three, and 4 in three; and was identical in the two groups of patients. The $\mathrm{FEV}_{1}$ values were identical in both groups (mean \pm SEM $85 \pm 5$ versus $82 \pm 4 \%$ pred). There was no observed difference in gradient efficiency between healthy subjects, stable and unstable asthmatic patients, i.e. the number of each cell population recovered was always statistically identical.

Table 1. - Characterization of asthmatic patients

\begin{tabular}{|c|c|c|c|c|c|c|}
\hline $\begin{array}{l}\text { Patient } \\
\mathrm{N}^{\circ}\end{array}$ & $\begin{array}{l}\text { Age } \\
\text { yrs }\end{array}$ & Sex & $\begin{array}{c}\text { Time since } \\
\text { last attack } \\
\mathrm{h}\end{array}$ & Allergy & $\begin{array}{l}\mathrm{FEV}_{1} \\
\% \text { pred }\end{array}$ & $\begin{array}{l}\text { Severity } \\
\text { Aas' score }\end{array}$ \\
\hline \multicolumn{7}{|c|}{ Unstable } \\
\hline 1 & 19 & M & 18 & + & 100 & 1 \\
\hline 2 & 45 & F & 24 & + & 100 & 1 \\
\hline 3 & 27 & $\mathrm{~F}$ & 12 & + & 80 & 3 \\
\hline 4 & 36 & $\mathrm{~F}$ & 24 & + & 74 & 4 \\
\hline 5 & 55 & $\mathrm{~F}$ & 18 & - & 100 & 2 \\
\hline 6 & 22 & $\mathrm{~F}$ & 24 & - & 75 & 2 \\
\hline 7 & 60 & M & 12 & - & 70 & 3 \\
\hline \multicolumn{7}{|l|}{ Stable } \\
\hline 8 & 33 & M & - & + & 100 & 1 \\
\hline 9 & 52 & $\mathrm{~F}$ & - & + & 80 & 2 \\
\hline 10 & 33 & M & - & - & 85 & 1 \\
\hline 11 & 50 & F & - & - & 100 & 2 \\
\hline 12 & 62 & $\mathrm{~F}$ & - & - & 75 & 3 \\
\hline 13 & 58 & $\mathrm{~F}$ & - & - & 69 & 4 \\
\hline 14 & 66 & M & - & - & 70 & 4 \\
\hline
\end{tabular}

$\mathrm{FEV}_{1}$ : forced expiratory volume in one second; $\%$ pred: percentage of predicted value; $\mathrm{M}$ : male; F: female; +: positive; -: negative; Aas' score: clinical score used to grade chronic asthma from very mild form ( $\mathrm{score}=1$ ) to incapacitating disease requiring permanent medication (score $=5$ ). 


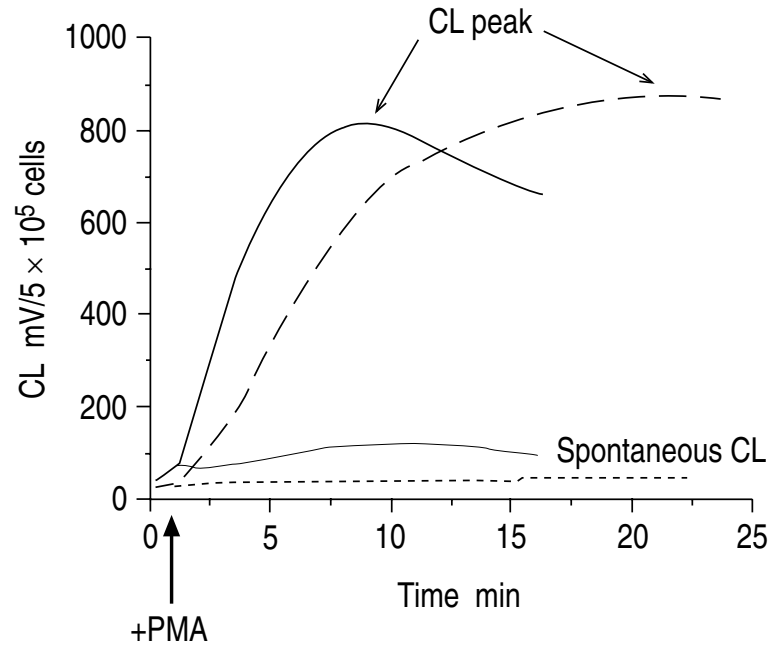

Fig. 1. - Kinetic curve of lucigenin $\left(10^{-5} \mathrm{~mol} \cdot l^{-1}\right)$ enhanced chemiluminescence $(\mathrm{CL})$ on $5 \times 10^{5} \mathrm{PMNs}$ or Mos before and after stimulation with PMA $\left(10^{-7} \mathrm{~mol} \cdot l^{-1}\right)$ added after the first measurement made at time 0. Bold line represents the kinetic curve for PMAstimulated PMNs (continuous line) and stimulated Mos (broken line). Normal line represents the kinetic curve for nonstimulated PMNs (continuous) and Mos (dotted). PMA: phorbol myristate acetate; PMNs: polymorphonuclear neutrophils; Mos: monocytes.

\section{Analysis of CL results}

Figures 1 and 2 show the time course variations in CL of PMNs and Mos in lucigenin and luminol, respectively. As indicated in the Methods section, the CL peak was defined as the maximal CL value obtained after PMA-stimulation.

Lucigenin-dependent CL (fig. 3). Nonstimulated PMNs and Mos from asthmatic patients released significantly higher quantities of $\mathrm{O}_{2} \cdot^{-}$than those from healthy

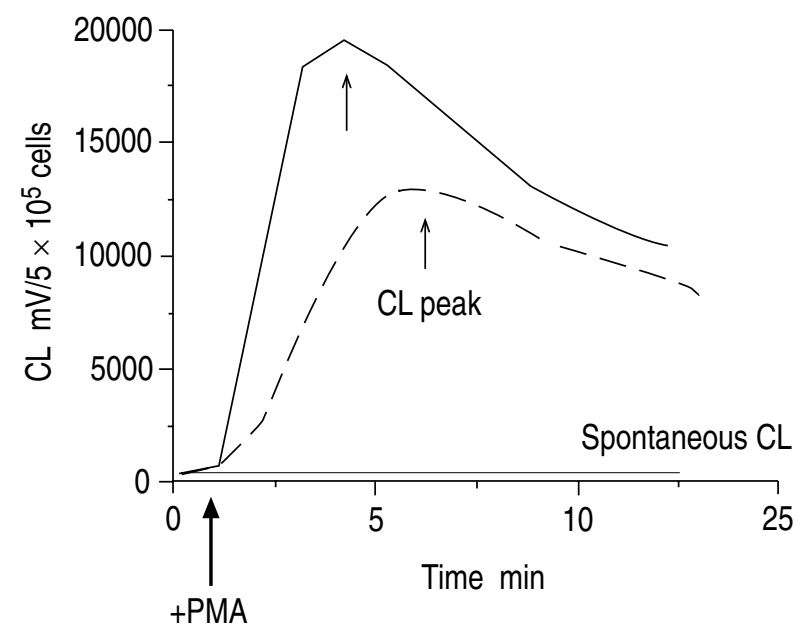

Fig. 2. - Kinetic curve of luminol $\left(10^{-4} \mathrm{~mol} \cdot \mathrm{l}^{-1}\right)$ enhanced chemiluminescence $(\mathrm{CL})$ on $5 \times 10^{5} \mathrm{PMNs}$ or Mos before and after stimulation with PMA $\left(10^{-7} \mathrm{~mol} \cdot l^{-1}\right)$ added after the first measurement made at time 0. Bold line represents the kinetic curve for PMAstimulated PMNs (continuous line) and stimulated Mos (broken line). Normal line represents the kinetic curve for nonstimulated PMNs and Mos. For abbreviations see legend to figure 1.

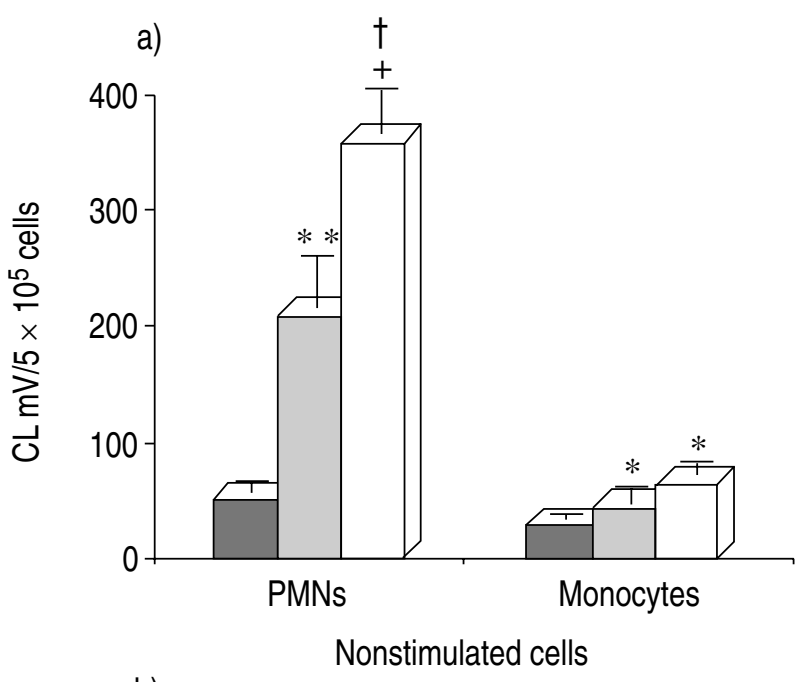

b)

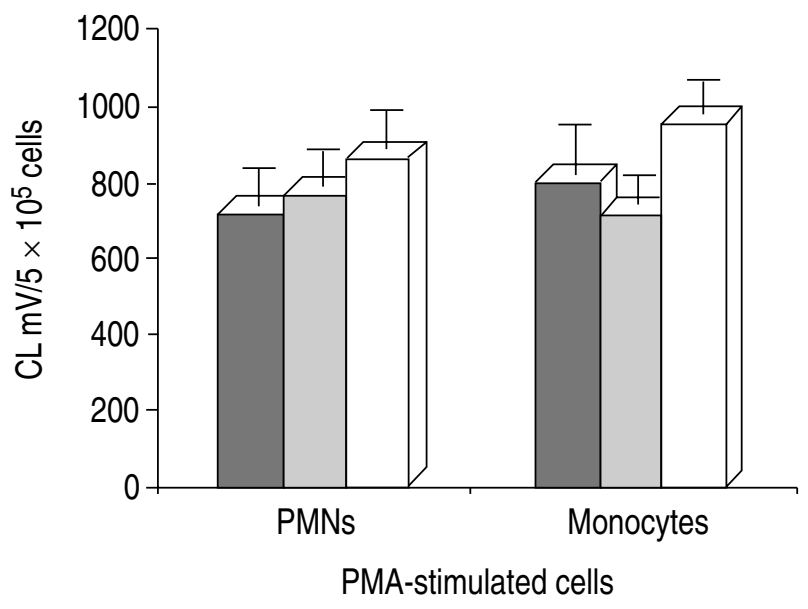

Fig. 3. - Chemiluminescence (CL) peaks of superoxide anion generation using luminometer analysis on PMNs and Mos. Lucigenin $\left(10^{-5} \mathrm{~mol} \cdot l^{-1}\right)$ was used as enhancer for the CL analysis. Cells were purified from whole blood using a Percoll gradient and suspended in medium $\left(5 \times 10^{5}\right.$ cells $\left.\mathrm{ml}^{-1}\right)$. a) Lucigenin was added for nonstimulated cells, and measurements were carried out every minute until CL peak appeared. b) Lucigenin was added for PMA-stimulated cells, and a first measurement was taken. PMA $\left(10^{-7} \mathrm{~mol} \cdot l^{-1}\right)$ was then added, and the measurements were carried out every min until a CL peak appeared. Results were expressed as $\mathrm{mV} / 5 \times 10^{5}$ cells (mean \pm SEM). $*: \mathrm{p}<0.05$; **: $\mathrm{p}<0.005 ;+$ : $\mathrm{p}<0.001$, for significant differences from healthy subjects. $\dagger: p<0.05$, for significant differences between stable and unstable asthmatic patients. $\square$ : healthy; $\square$ : stable asthma; $\square$ : unstable asthma. For abbreviations see legend to figure 1 .

subjects. This was particularly evident in cells from unstable asthmatic patients $(\mathrm{p}<0.001$ and $\mathrm{p}<0.05$ for PMNs and Mos, respectively), and from stable asthmatic patients $(\mathrm{p}<0.005$ and $\mathrm{p}<0.05$, respectively). There was a significant difference between stable and unstable asthmatic patients for PMNs $(\mathrm{p}<0.05)$, with no significant difference for Mos. Moreover, PMNs released significantly higher quantities of ROS than did Mos in the three groups of subjects.

In PMA-stimulated cells, no significant difference was observed between the three populations of subjects, and the results were almost identical for PMNs and Mos. 


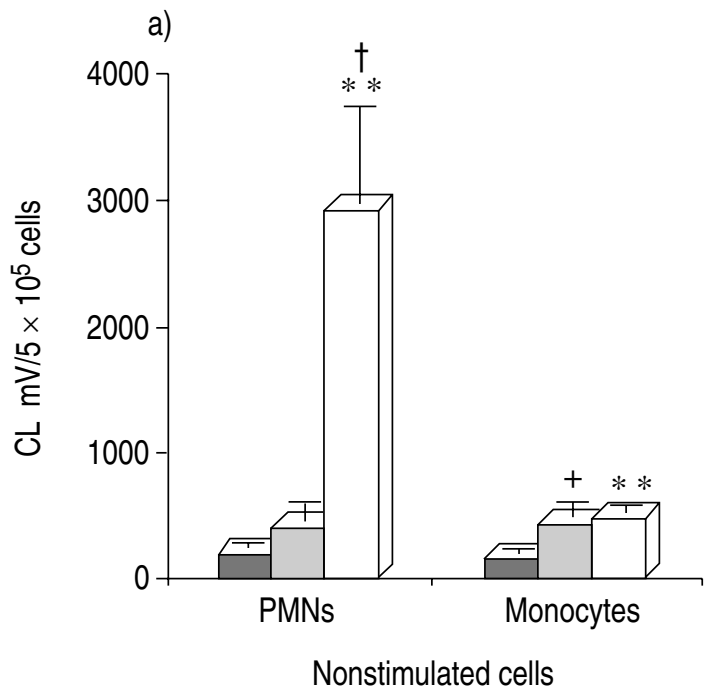

b)

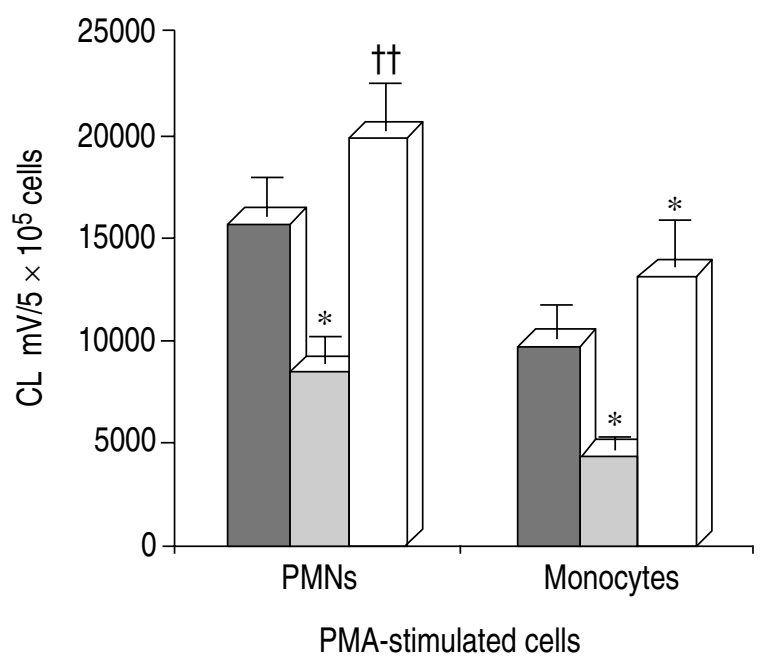

Fig. 4. - Chemiluminescence (CL) peaks of the whole set of reactive oxygen species generation using luminometer analysis on PMNs and Mos. Luminol $\left(10^{-4} \mathrm{~mol} \cdot l^{-1}\right)$ was used as enhancer for the CL analysis. Cells were purified from whole blood using a Percoll gradient and suspended in medium $\left(5 \times 10^{5}\right.$ cells $\left.\mathrm{ml}^{-1}\right)$. a) Luminol was added for nonstimulated cells, and measurements were carried out every min until CL peak appeared. b) Luminol was added for PMA-stimulated cells, and a first measurement was taken. PMA $\left(10^{-7} \mathrm{~mol} \cdot \mathrm{l}^{-1}\right)$ was then added, and the measurements were carried out every minute until a CL peak appeared. The results were expressed as $\mathrm{mV} 5 \times 10^{5}$ cells (mean \pm SEM). $*$ : $\mathrm{p}<0.05$;**: $\mathrm{p}<0.01$; and $+: \mathrm{p}<0.001$, for significant differences from healthy subjects. $\dagger: \mathrm{p}<0.05$; and $\dagger \dagger: \mathrm{p}<0.01$, for significant differences between stable and unstable asthmatic patients. $\square$ : healthy; $\square$ : stable asthma; $\square$ : unstable asthma. For abbreviations see legend to figure 1 .

Luminol-dependent CL (fig. 4). Nonstimulated PMNs from unstable asthmatic patients released significantly higher quantities of ROS than those from healthy subjects $(p<0.01)$. Nonstimulated Mos from asthmatic patients, either in a stable or unstable state, released higher quantities of ROS than healthy subjects $(\mathrm{p}<0.01$ and $\mathrm{p}<0.001$, respectively). Moreover, the difference between stable and unstable asthmatic patients was significant for PMNs $(\mathrm{p}<0.05)$ but nonsignificant for Mos.
When PMNs or Mos were stimulated by PMA, the responses were almost identical in unstable asthmatic patients and healthy subjects, whereas there was a significantly lower CL response in stable asthmatic patients $(\mathrm{p}<0.05)$. There were significant differences between stable and unstable asthmatic patients for PMNs $(\mathrm{p}<0.001)$, and for Mos $(\mathrm{p}<0.01)$.

\section{$\beta_{2}$-agonist inhalation effects}

No effect was observed on the efficiency gradient and on the numbers of each cell population before and after inhalation. Thirty minutes after $\beta_{2}$-agonist inhalation, PMA-stimulated PMNs and Mos showed 20-30\%

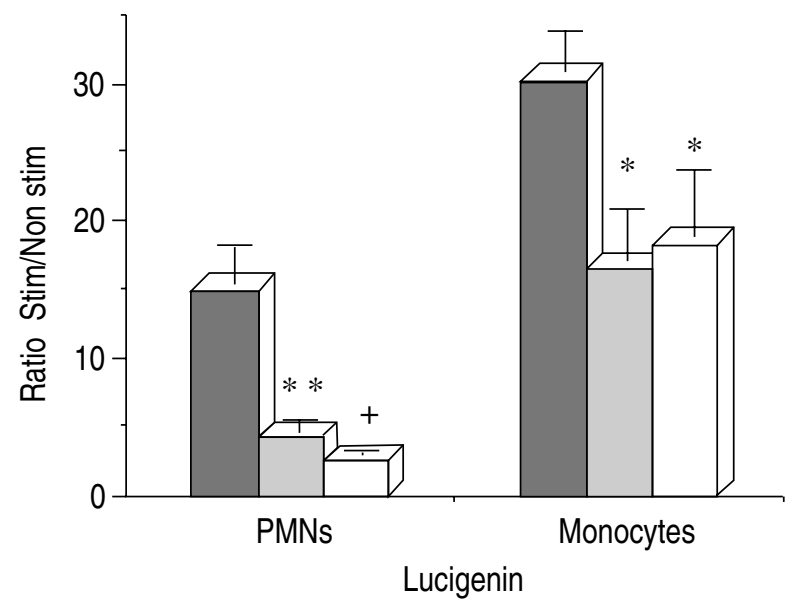

Fig. 5. - Ratio of PMA-stimulated cells versus nonstimulated cells for PMNs and Mos, to analyse the coefficient of stimulatability of superoxide anion using lucigenin $\left(10^{-5} \mathrm{~mol} \cdot l^{-1}\right)$ enhanced chemiluminescence (CL). Results are expressed as the ratio of PMA-stimulated/nonstimulated CL peak (mean \pm sEM). $*$ : $p<0.05 ; * *: p<0.005 ;+$ : $p<0.001$, for significant differences from healthy subjects. $\square$ : healthy; $\square$ : stable asthma; $\square$ : unstable asthma; Stim: stimulated. For abbreviations see legend to figure 1.

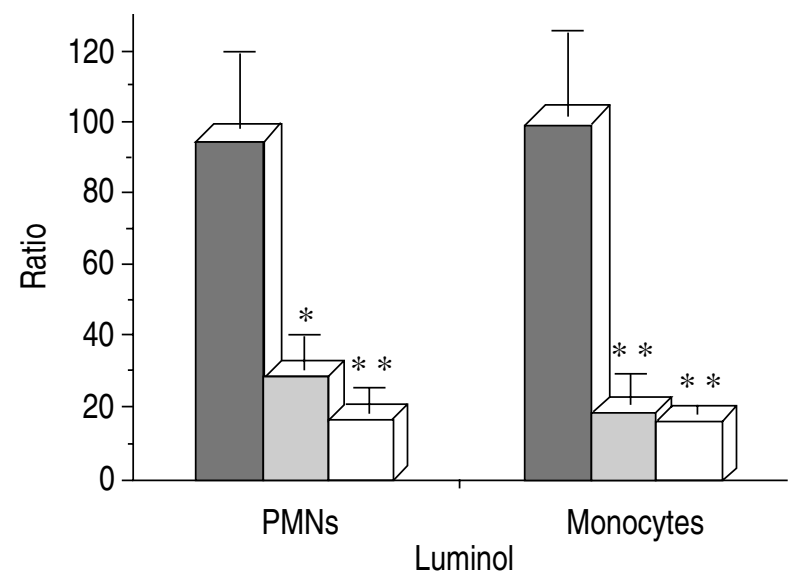

Fig. 6. - Ratio of PMA-stimulated cells versus nonstimulated cells for PMNs and Mos, to analyse the coefficient of stimulatability of the whole set of reactive oxygen species using luminol $\left(10^{-4} \mathrm{~mol} \cdot \mathrm{l}^{-1}\right)$ enhanced chemiluminescence (CL). Results are expressed as the ratio of PMAstimulated/nonstimulated CL peak (mean \pm SEM). *: $\mathrm{p}<0.05 ; * *: \mathrm{p}<0.01$, for significant differences from healthy subjects. $\square$ : healthy; $\square$ : stable asthma; $\square$ : unstable asthma. For abbreviations see legend to figure 1 . 
decrease in ROS release assessed by lucigenin and luminol enhanced CL, whilst no effect was observed on nonstimulated cells (data not shown).

\section{Analysis of stimulatability coefficient}

Lucigenin-dependent CL. As reported in figure 5, the ratio of PMNs and Mos was significantly greater in healthy subjects than in stable asthmatic patients $(\mathrm{p}<0.005$ for PMNs and $\mathrm{p}<0.05$ for Mos), or unstable asthmatic patients $(\mathrm{p}<0.001$ for PMNs and $\mathrm{p}<0.05$ for Mos). Moreover, it was higher for Mos than PMNs in all groups of patients.

Luminol-dependent $C L$. As reported in figure 6, the ratio was significantly greater in PMNs and Mos from healthy subjects than from stable asthmatic patients ( $\mathrm{p}<0.05$ for PMNs and $\mathrm{p}<0.01$ for Mos) or unstable asthmatic patients $(\mathrm{p}<0.01$ for both cell types).

In both, luminol and lucigenin, there were no significant differences between stable and unstable asthmatic patients.

\section{Discussion}

This study demonstrated that in comparison to healthy subjects, nonstimulated PMNs and Mos from asthmatic patients released higher quantities of $\mathrm{O}_{2} \cdot^{-}$and the whole set of ROS as assessed by lucigenin and luminol enhanced CL, respectively. This difference was more pronounced in cells from unstable asthmatic patients than from stable asthmatic patients for Mos, and even more so for PMNs.

This increase in ROS release was not correlated with the severity of asthma as defined by the Aas' score [3] and $\mathrm{FEV}_{1}$. Reactivity of circulating PMNs and Mos differed from that observed by CLUZEL et al. [2] on human alveolar macrophages. They showed that alveolar macrophages released higher amounts of ROS, which were correlated with the severity of asthma. In fact, the activation state of alveolar macrophages according to severity cannot only be explained by the migration of blood monocytes. It appears that the high number of eosinophils, observed in bronchoalveolar fluid and bronchial biopsies [21] according to the severity of asthma, could explain this increased activation.

Our results obtained for PMNs in asthma are in agreement with those obtained by KaTO et al. [22], and NeIJfEns et al. [5]. The results of KATO et al. [22] suggested that PMNs in asthmatic children, especially those with attacks, generate more ROS than those of healthy subjects, as assessed by a cypridina luciferin analogue enhanced CL. NEIJFENS et al. [5] suggested that the increased generation of ROS in children with asthma might also contribute to causing bronchial hyperresponsiveness (BHR).

We also demonstrated that increased generation in unstable asthmatic patients was not the consequence of $\beta_{2}$-agonist inhalation. This is in accordance with previous studies investigating effect of $\beta_{2}$-agonists on the generation of ROS from neutrophils in vitro [23], and from eosinophils in vitro [24] and ex-vivo [25].

Results obtained in stable asthmatic patients with nonstimulated PMNs and Mos showed increased generation of ROS, as assessed by lucigenin and luminol enhanced CL. This observation suggests that PMNs and Mos could be primed in vivo, as observed for alveolar macrophages by JoHNSTON and KITAGAwA [26]. However, we cannot say whether this priming was the result of an intrinsic defect in regulation of the cell or the effect of other mediator(s) remaining present after an asthma attack.

After PMA-stimulation, the stimulatability coefficient was higher in PMNs and Mos from healthy subjects than from asthmatic patients, and was identical in both asthmatic patient populations for lucigenin and luminol enhanced CL. Similar results have previously been observed for other mediators, namely that the spontaneous release of mediators by "resting cells" may be very high, without modification of the total release after PMA-stimulation. This has been observed with alveolar macrophages, either for interleukin-1 (IL-1) release by Pujol et al. [27], or for phosphoinositide turnover by DAMON et al. [28].

The CL peak of PMA-stimulated PMNs and Mos for ROS release as assessed by luminol enhanced CL in stable asthmatic patients was significantly lower as compared to healthy subjects or unstable asthmatic patients. However, the $\mathrm{O}_{2} .^{-}$release as assessed by lucigenin enhanced CL was identical in the three groups of subjects. In stable asthmatic patients, PMNs and Mos appeared to be already primed but less stimulatable before asthma attack. These data indicate different release of $\mathrm{O}_{2} .^{-}$and of other ROS in stable asthmatic patients. This could suggest that in unstable asthmatic patients, non- $\mathrm{O}_{2} \cdot^{-}$ROS generation could be regulated and/or controlled by a different mechanism.

Resting PMNs released greater amounts of $\mathrm{O}_{2} \cdot{ }^{-}$as assessed by lucigenin enhanced CL and greater amounts of ROS as assessed by luminol enhanced CL than did Mos. However, after PMA-stimulation, the amounts of $\mathrm{O}_{2}$ - $^{-}$ and ROS were almost identical in the both cell populations. This difference in stimulatability between PMNs and Mos could be the consequence of different enzyme equipment or activity in both cells populations. It is well-known that Mos contains less myeloperoxide (MPO) than PMNs [29], but they contain a peroxidase in cytoplasmic granules which is almost identical to that of the MPO of neutrophils [30]. Could this be related to the different functions of the two cell populations in asthma? Mos are known to be primed [4] and to immigrate into the lungs and form the alveolar macrophage pool [31]. It is possible that PMNs only play a role at the time of antigen challenge to mediate the airway response [32]. The results of HutCHINSON et al. [33] indicate that the effects of PMNs present in the lungs can potentiate the effect on the endothelial compartment, and that circulating PMNs could then be more effective. This would suggest that PMNs have more important 
deleterious effects in blood than in the lung tissues. Moreover, KelLenBACH et al. [34] and others have also shown a fast PMN recruitment following exercise allergen challenge after bronchoprovocation in asthma.

We would like to propose the hypothesis that PMNs could be implicated in endothelial injury and increased vascular permeability. Indeed, LASSALLE et al. [35] showed that activated endothelial cells could enhance PMN migration and protect themselves against potential damaging effects of metabolites produced by PMNs during transvascular migration. PARKer et al. [36] showed that the eosinophil peroxide (EPO)- $\mathrm{H}_{2} \mathrm{O}_{2}$-halide system was a significant contributor to the increased vascular permeability induced by PMA-activated eosinophils, and that EPO-generated hypohalous acids could significantly contribute to endothelial injury in bronchial asthma.

Severity and activity of asthma did not have the same pathophysiological significance. Blood PMNs and Mos seemed to be primed for Ros production in both groups of asthmatic patients, but more pronounced in unstable patients; in stable asthmatic patients, however, these cells were less stimulatable for non $\mathrm{O}_{2} \cdot-$ Ros production. PMNs and Mos appeared to react differently, and additional studies are required to better understand their relative importance in the vascular and cellular components of inflammation observed in bronchial asthma. We have shown that CL measurements can reflect the activity of asthma in individual patients. Further investigations of whole blood samples during a time course study should provide interesting information.

\section{References}

1. Jeffrey PK, Wardlam AJ, Nelson FC, Collins JV, Kay AB. Bronchial biopsies in asthma. Am Rev Respir Dis 1989; 140: 1745-1753.

2. Cluzel M, Damon M, Chanez P, et al. Enhanced alveolar cell luminol dependent chemiluminescence in asthma. J Allergy Clin Immunol 1987; 80: 195-201.

3. Aas K. Heterogeneity of bronchial asthma. Subpopulation or different stages of the disease. Allergy 1981; 36: $3-14$

4. Vachier I, Damon M, Le Doucen C, et al. Increased oxygen species generation in blood monocytes of asthmatic patients. Am Rev Respir Dis 1992; 146: 1161-1166.

5. Neijfens HJ, Raatgeep RE, Degenhart HJ, Duiverman EJ, Kerrebijn KF. Altered leukocyte response in relation to the basic abnormality in children with asthma and bronchial hyperresponsiveness. Am Rev Respir Dis 1984; 130: 744-747.

6. Meltzer S, Goldberg B, Lad P, Easton J. Superoxide generation and its modulation by adenosine in the neutrophils of subjects with asthma. J Allergy Clin Immunol 1989; 83: 960-966.

7. Klebanoff SJ, Phagocytic cells: products of oxygen metabolism. In: Gallin JL, Goldstein IM, Snyderman R, eds. Inflammation, Basic Principles and Clinical Correlates. New York, Raven Press, 1988; pp. 391-444.

8. Warren N, Jones AE, Bater AJ. Three-peaked chemiluminescent response of human peripheral blood leukocytes following stimulation with phytohaemagglutinin (PHA). J Biolum Chemilum 1990; 5: 235241.
9. Doelman CJA, Bast A. Oxygen radicals in lung pathology. Free Rad Biol Med 1990; 9: 381-400.

10. Allen RC. Phagocytic leukocyte oxygenation activities and chemiluminescence: a kinetic approach to analysis. Methods Enzymol 1986; 133: 449-493.

11. Turner Warwick M. Epidemiology of nocturnal asthma. Am J Med 1988; 85 (Suppl. 1B): 6-8.

12. Chanez P, Bousquet J, Couret I, et al. Increased numbers of hypodense alveolar macrophages in patients with bronchial asthma. Am Rev Respir Dis 1991; 144: 923-930.

13. Heyworth PG, Segal AW. Further evidence for the envolvement of a phosphoprotein in the respiratory burst oxidase of human neutrophils. Biochem J 1986; 239: 723-731.

14. Nakamura M, Baxter CR, Master BSS. Simultaneous demonstration of phagocytosis-connected oxygen consumption and corresponding NAD(P)H oxidase activity: direct evidence for NADPH as the predominant electron donor to oxygen in phagocytozing human neutrophils. Biochem Biophys Res Commun 1981; 98: 743-751.

15. American Thoracic Society. Standard for diagnosis and care of patients with chronic obstructive pulmonary disease (COPD) and asthma. Am Rev Respir Dis 1987; 136: 225-245.

16. Robert RL, Gallin JI. Rapid method for isolation of normal human peripheral blood eosinophils on discontinuous Percoll gradients and comparison with neutrophils. Blood 1985; 65: 433-440.

17. Samuni A, Krishna CM, Cook J, Black CDV, Russo A. On radical production by PMA-stimulated neutrophils as monitored by luminol-amplified chemiluminescence. Free Rad Biol Med 1991; 10: 305-313.

18. Johansson A, Dahlgren C. Luminol-amplified chemiluminescence activity in human monocytes: a comparison with the activity induced in granulocytes. $J$ Biolum Chemilum 1990; 5: 37-41.

19. Minkenberg I, Feber E. Lucigenin-dependent chemiluminescence as a new assay for NAD(P)H-oxidase activity in particulate fractions of human polymorphonuclear leukocytes. J Immunol Meth 1984; 71: 61-67.

20. Trulson A, Nilsson S, Venge P. Lucigenin-enhanced chemiluminescence in blood is increased in cancer. $\mathrm{Am}$ J Clin Pathol 1989; 91: 441-445.

21. Bousquet J, Chanez P, Lacoste JY, et al. Eosinophilic inflammation in asthma. N Engl J Med 1990; 323: 1033-1039.

22. Kato M, Nakano M, Morikawa A, Kimura H, Shigeta M, Kuroume T. Ability of polymorphonuclear leukocytes to generate active oxygen species in children with bronchial asthma: use of chemiluminescence probes with a cypridina luciferin analog and luminol. Int Arch Allergy Appl Immunol 1991; 95: 17-22.

23. Wong K, Freund K. Inhibition of N-formyl methionylleucyl-phenylalanine-induced respiratory burst in human neutrophils by adrenergic agonist and prostaglandins of the E series. Can J Physiol Pharmacol 1981; 59: 915-920.

24. Yukawa T, Ukena D, Kroegel C, et al. Beta -adrenergic $^{-}$ receptors on eosinophils. Binding and functional studies. Am Rev Respir Dis 1990; 141: 1446-1452.

25. Okada C, Sugiyama H, Eda R, et al. Effect of formoterol on superoxide anion generation from bronchoalveolar lavage cells after antigen challenge in guinea-pigs. $\mathrm{Am}$ J Respir Cell Mol Biol 1993; 8: 509-517.

26. Johnston RB, Kitagawa S. Molecular basis for enhanced respiratory burst of activated macrophages. Fed Proc 1985; 44: 2927-2932. 
27. Pujol JL, Cosso B, Daures JP, Clot J, Michel FB, Godard P. Interleukin-1 release by alveolar macrophages in asthmatic patients and healthy subjects. Int Arch Allergy Appl Immunol 1990; 91: 207-210.

28. Damon M, Vial H, Crastes de Paulet A, Godard P. Phosphoinositide breakdown and superoxide anion release in formyl-peptide-stimulated human alveolar macrophages: comparison between quiescent and activated cells. FEBS Lett 1988; 239: 169-173.

29. Nichols BA, Bainton DF. Differentiation of human monocytes in bone marrow and blood sequentiel formation of two granule populations. Lab Invest 1973; 29 27-40.

30. Bos A, Wever R, Roos D. Characterization and quantification of the peroxidase in human monocytes. Biochim Biophys Acta 1978; 525: 37-44.

31. Adams DO, Hamilton TA. The cell biology of macrophage activation. Annu Rev Immunol 1984; 2: 282318 .
32. Murphy KR, Wilson MC, Irvin CG. The requirement for polymorphonuclear leukocytes in the late asthmatic response and heightened airways reactivity in an animal model. Am Rev Respir Dis 1986; 134: 62-68.

33. Hutchinson AA, Hinson JM Jr, Brigham KL, Snapper JR. Effect of endotoxin on airway responsiveness to aerosol histamine in sheep. J Appl Physiol: Respirat Environ Exercise Physiol 1983; 54: 1463-1468.

34. Kellenbach J, Baynes R, Fine B, Dajee B, Bezwoda W. Persistent neutrophils activation in mild asthma. J Allergy Clin Immunol 1992; 90: 272-274.

35. Lassalle $\mathrm{Ph}$, Delneste $\mathrm{Y}$, Gosset $\mathrm{Ph}$, et al. Neutrophilendothelial cell interaction: evidence in vitro for a regulation by endothelial cells of neutrophil functions. Eur Respir J 1991; 4: 1251-1257.

36. Yoshigawa S, Kayes SG, Parker JC. Eosinophils increase lung microvascular permeability via the peroxidasehydrogen peroxidase-halide system. Am Rev Respir Dis 1993; 147: 914-920. 